\title{
TEXTURE IN METALLIC AND CERAMIC FILMS AND COATINGS
}

\author{
F. CZERWINSKI * and J.A. SZPUNAR \\ Department of Metallurgical Engineering, McGill University, \\ 3450 University street, Montreal, Quebec, H3A 2B2 Canada
}

(Received in final form 28 September 1997)

\begin{abstract}
The properties of films and coatings can be optimized for a variety of applications by modifying their texture. Understanding how the texture in thin films is formed and how it can be controlled during film growth process is one of the most important areas of texture research. Several examples were selected to illustrate how the texture in films and coatings is developed and to explain how various properties of films are affected by texture. In particular, texture development during electrodeposition of $\mathrm{Zn}$-based automobile coatings, $\mathrm{Ni}$ and Ni-based layers for magnetic recording as well as $\mathrm{Fe}$ and $\mathrm{Fe}$-based wearresistant coatings, is presented. A new area of application of texture research to control the high-temperature oxidation resistance of engineering materials is described. Using experimental data for $\mathrm{Ni}$ and $\mathrm{Ti}$, the factors affecting texture formation during growth of ceramic oxides are discussed, with special attention paid to the role of substrate texture. The correlation between the oxide texture, grain boundary structure and diffusion of metal and oxygen ions at high temperatures, is considered.
\end{abstract}

Keywords: Thin films; Coatings; Electrodeposition; High-temperature oxidation

\section{INTRODUCTION}

More than seventy years ago, Volmer (1921) reported that zinc crystals grown from a vapour beam had a preferred orientation with respect to the vapour beam direction. Since that time, numerous observations of preferred orientations have been made, not only in films deposited from the vapour phase, but also manufactured by other techniques, including electrodeposition from aqueous solutions. In fact, it is rather difficult to

\footnotetext{
* Corresponding author. On leave from the University of Mining and Metallurgy, Cracow, Poland.
} 
produce the films and coatings without texture because the crystallites of a metallic electrodeposit are never randomly oriented. They very often exhibit a one-degree orientation in such a way that every crystallite has tendency to possess a definite crystallographic axis along the electric field direction. This tendency is more or less pronounced, according to the nature of the metal being deposited and deposition conditions.

Recently, texture in non-metallic materials is attracting considerable interest because it is related to new properties and technological applications. Texture in ceramics was studied, mainly in hard magnetic materials, but also in high-temperature superconductors, ferroelectric, transformation-toughened ceramics and in surface layers of corrosive oxides (Bunge, 1991). In general, the ceramic materials have lower crystal symmetries than metals and the anisotropy of many of their physical properties is much stronger. It is expected, therefore, that there will be also stronger influence of texture on the properties of ceramics than in highly symmetric metals.

Some examples of our research related to texture in surface films and coatings, both metallic and ceramic, are presented and discussed in this paper.

\section{TEXTURE OF ELECTROLYTIC Ni, Fe AND Ni-Fe ALLOY COATINGS}

Ni-based (f.c.c.) electrodeposits are known for giving numerous, welldefined preferred orientations. Many theoretical explanations have been put forward to account for the different textures experimentally observed. They are based on the standpoints of: (i) competitive nucleation (Pangarov, 1962); (ii) growth competition (Reddy, 1963) and (iii) inhibited deposition (Amblard et al., 1977). While the first two theories favour a free mode of growth, the latter favours a hindered growth and a strong interaction between the metallic surface and some chemical species capable of being adsorbed upon it. However, none of these single theories can predict the complete set of texture results now available. For example, according to the theory of oriented nucleation, an increase in cathodic potential causes texture formation in f.c.c. metals in the following sequence: $\langle 111\rangle,\langle 100\rangle,\langle 110\rangle,\langle 311\rangle$ and 
$\langle 210\rangle$ (Pangarov, 1962). For conditions of increasing potential, the theory of inhibited growth predicts the sequence: $\langle 110\rangle,\langle 100\rangle$ and $\langle 210\rangle$ (Amblard et al., 1977). Alloying of $\mathrm{Ni}$ with $\mathrm{Fe}$, in f.c.c. region of the phase diagram, should not change the type of texture generated in pure Ni. Thus, the texture measured in nanocrystalline $\mathrm{Ni}-45 \% \mathrm{Fe}$ (Czerwinski et al., 1997c), which consisted of two major fibre components, $\langle 100\rangle$ and $\langle 111\rangle$, does not exactly agree with the texture predicted (Fig. 1(a)). According to theory of competitive nucleation, the $\langle 111\rangle$ and $\langle 100\rangle$ textures should not be formed at a high cathode polarization usually applied during deposition of nanocrystals. On the other hand, in the theory of inhibited deposition, the $\left\langle\begin{array}{lll}1 & 1 & 1\end{array}\right\rangle$ direction is not preferential for growth of Ni (Fig. 1(b)).

The texture development during Fe electrodeposition was simulated using a Monte Carlo method (Li and Szpunar, 1997a,b). The simulation illustrated that the surface energy anisotropy played an important role in the formation of fibre texture, and that the texture changed with the current density, electrolyte temperature and the $\mathrm{pH}$ value. Increase in current density changed the texture in the following order: $\langle 110\rangle-$ $\langle 111\rangle-\langle 311\rangle$. At the same time, increase in $\mathrm{pH}$ caused the texture changes in direction $\langle 311\rangle-\left\langle\begin{array}{lll}1 & 1 & 1\end{array}\right\rangle-\langle 110\rangle$. Similarly, as in the case of

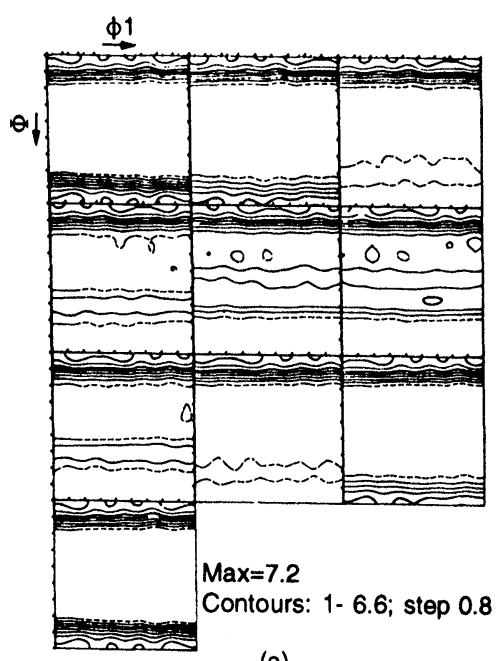

(a)

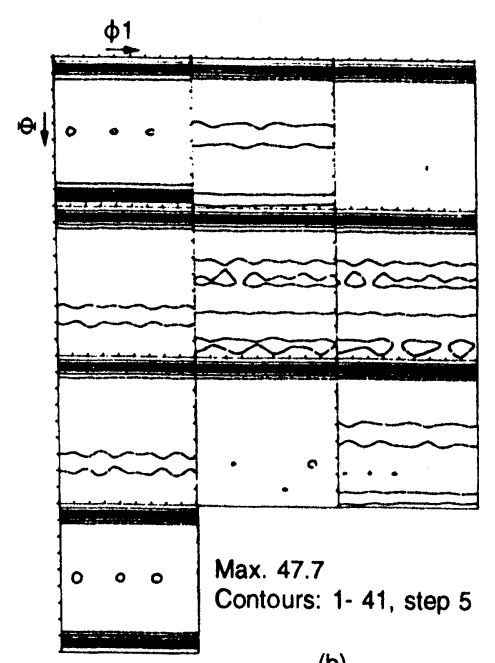

(b)

FIGURE 1 ODF of electrolytic Fe-45\%Ni coating with $\langle 1111\rangle+\langle 100\rangle$ fibre texture (a) and electrolytic Ni with strong $\langle 100\rangle$ fibre (b). 
alloying $\mathrm{Ni}$ with iron, the process of alloying iron with $\mathrm{Ni}$ in b.c.c. range did not change textures typical for pure iron. $\mathrm{Fe}-\mathrm{Ni}$ alloys with b.c.c. structure and coarse grains exhibit a $\left\langle\begin{array}{lll}1 & 1 & 0\rangle\end{array}\right.$ fibre, while the same alloys with nanosize grains have a $\left\langle\begin{array}{llll}1 & 1 & 1\end{array}\right\rangle$ fibre texture (Czerwinski et al., 1996b).

\section{TEXTURE OF Zn-BASED COATINGS}

Zn-based coatings have found applications in automotive industry. It was already demonstrated that the corrosion current for zinc coated steel in $\mathrm{NaOH}$ solutions is strongly affected by the coating texture (Vlad et al., 1987). In particular, zinc grains with a near $(00 \cdot 1)$ orientation have much lower corrosion currents when compared with those of other orientations. The role of texture in corrosion behaviour is explained both in terms of crack initiation and metal dissolution. There is another aspect of texture related behaviour. Namely, zinc-coated steel sheets are rarely used in the unpainted conditions. For cosmetic appearance and for increased corrosion resistance, the steel sheets are painted before they are subjected to further processing. Leidheiser and Kim (1956) showed that the paintability of zinc-coated steel sheets is greatly affected by texture. As in the case of corrosion resistance, the zinc grains with $(00 \cdot 1)$ orientation parallel to the sheet surface, have better paint adherence properties than those of other orientations.

Texture of electrolytic $\mathrm{Zn}$-based coatings is affected by current density and electrolyte temperature and composition (Park et al., 1996). According to findings by Kondo (1994), trace additions of some elements are especially effective in changing texture. In Fig. 2 there are shown $\mathrm{X}$-ray diffraction data for two $\mathrm{Zn}-\mathrm{Fe}$ alloys deposited without and with $\mathrm{Sn}^{2+}$ additions. The major difference between the X-ray diffraction patterns of both alloys, composed almost entirely of $\eta$ phase, is a drastic change in intensities of $(00 \cdot 1)$ and $(10 \cdot 1)$ peaks suggesting a change in crystallographic texture.

The pole figures of alloy deposited without $\mathrm{Sn}^{2+}$ show that the basal planes $(00 \cdot 1)$ of $\eta$ phase are inclined about $30-45^{\circ}$ to the substrate surface. An essentially different texture was detected in alloys deposited with addition of $\mathrm{Sn}^{2+}$ (Czerwinski et al., 1997a,b). In this case the basal planes of $\eta$ phase are aligned parallel to the substrate surface 


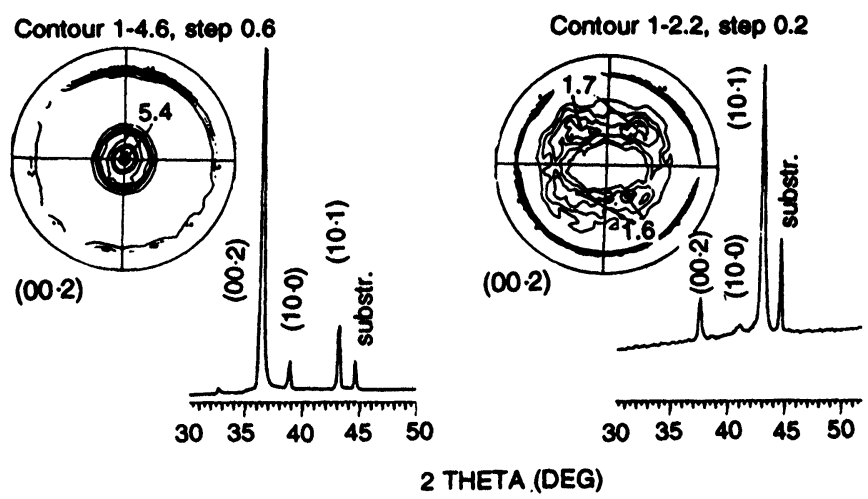

FIGURE 2 X-ray diffraction patterns and pole figures of $\mathrm{Zn}-\mathrm{Fe}$ alloy deposited with (a) and without (b) addition of $\mathrm{Sn}^{2+}$ ions (Czerwinski et al., 1997b).

(perpendicular to the growth direction). This is expressed by $\langle 00 \cdot 1\rangle$ fibre texture with a maximum intensity of 5.4 times random. The second texture component, $\mathrm{a}\langle 10.0\rangle$ fibre with the intensity of 1.2 times random, is weak. A strong fibre $\langle 00 \cdot 1\rangle$ texture is attributed to the morphology of hexagonal columnar crystals. This indicates that the hexagonal plates, consisting of (00.1) planes of $\eta$ phase, are aligned roughly parallel to the substrate surface (Czerwinski et al., 1997a). Conversely, the pole figure of alloy deposited without $\mathrm{Sn}^{2+}$ ions with a morphology of triangular pyramids, shows that the basal planes of $\eta$ phase are inclined to the substrate surface. This implies that the pyramids are surrounded by the $(00.1)$ and $(10.0)$ planes of $\eta$ phase. It is clear that the possibility of changing the texture and morphology of the $\mathrm{Zn}$-based coatings is of engineering importance. A $\langle 00 \cdot 1\rangle$ texture, formed after the addition of $\mathrm{Sn}^{2+}$ ions, is expected to provide a better corrosion resistance and paintability.

\section{FACTORS AFFECTING TEXTURE FORMATION DURING NICKEL OXIDATION}

As reported by Cathcart et al. (1969), high anisotropy also exists in oxidation resistance of different crystal planes in metals. According to our latest measurements on pure $\mathrm{Ni}$ at $973 \mathrm{~K}$, the oxide growth rate on 
(1 11 1) $\mathrm{Ni}$ is over one order of magnitude lower than that observed for (1 00)Ni (Czerwinski et al., 1995a; Czerwinski and Szpunar, 1998a). Despite the practical importance of the last finding, no attempt has been reported to modify the texture of metallic substrates to improve their corrosion resistance. In general, the oxide texture depends on substrate nature and growth parameters. To estimate the relative contribution of each individual factor, the surface of polycrystalline $\mathrm{Ni}$ was finished by two techniques: (i) mechanical polishing to introduce the physical damage and to promote the nucleation of randomly oriented oxide, and (ii) chemical polishing to reveal the atomic structure of the surface and to promote epitaxial growth (Czerwinski and Smeltzer, 1993). The morphologies of both $\mathrm{NiO}$ films exhibit essential differences. While $\mathrm{NiO}$ formed on mechanically polished substrate is uniform in thickness and does not reveal the influence of substrate crystallography, NiO formed after chemical polishing is highly nonuniform. The oxide thickness and morphology strongly depend on the orientation of $\mathrm{Ni}$ grains. Moreover, the morphological observation indicates that the $\mathrm{NiO}$ growth is also influenced by the type of $\mathrm{Ni}$ grain boundary.

The pole figures of $\mathrm{Ni}$ substrate and $\mathrm{NiO}$ films formed after both techniques of surface finishing also support the crucial role of substrate texture (Fig. 3). The texture of the Ni substrate is $\left\{\begin{array}{lll}1 & 0 & 0\end{array}\right\}\left\langle\begin{array}{ll}0 & 23\end{array}\right\rangle$ with a maximum intensity of 4.1 times random. Exposure to oxygen causes the individual $\mathrm{Ni}$ grains to oxidize at different rates. $\mathrm{NiO}$ texture $\{100\}\langle 013\rangle$ formed as a result of the exposure of Ni substrate for $35 \mathrm{~h}$ at $1073 \mathrm{~K}$ (Fig. 3(a)), supports the influence of epitaxy between the
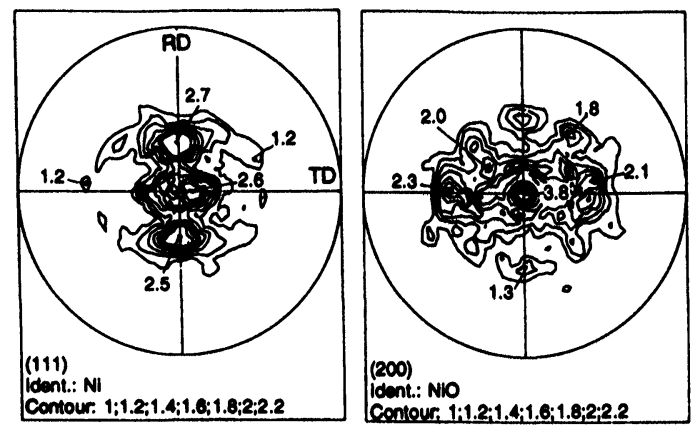

Contour; 1:1.2;1.4;1.6;1.8;2;2.2

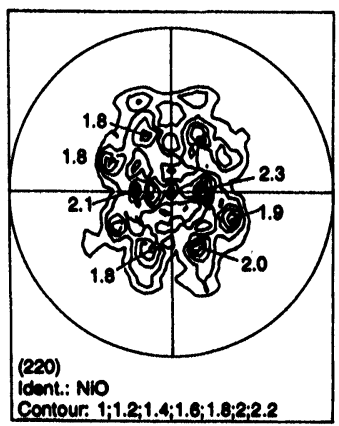

Contour: 1;1.2;1.4;1.6;1.8;2;2.2

FIGURE 3(a) 

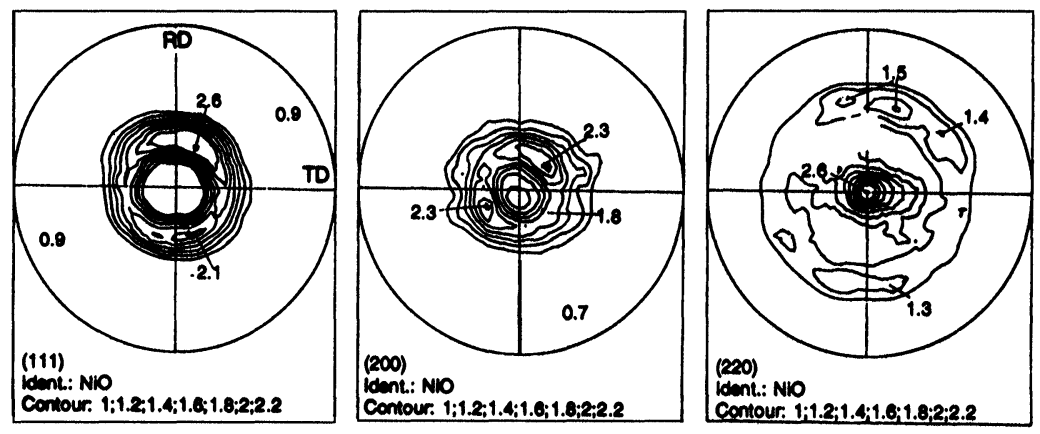

FIGURE 3(b)

FIGURE 3 Texture of $\mathrm{NiO}$ grown at $1073 \mathrm{~K}$ for $35 \mathrm{~h}$ in oxygen on Ni with surface finished by chemical polishing (a) and mechanical polishing (b).

oxide and substrate. Conversely, pole figures of $\mathrm{NiO}$ formed on mechanically polished $\mathrm{Ni}$ do not show the influence of the substrate (Fig. 3(b)). Instead, a weak $\langle 110\rangle$ fibre texture is developed. Since the initial $\mathrm{NiO}$ oxide formed on mechanically polished $\mathrm{Ni}$ surface is characterized by random distribution of grain orientations (Czerwinski et al., 1995b), the $\langle 110\rangle$ fibre is the growth texture of $\mathrm{NiO}$ developed under these experimental conditions.

\section{TEXTURE IN OXIDE FILMS GROWN ON TITANIUM}

Oxide films on titanium have an application in many areas of technology and medicine, including vacuum catalysis, aircraft construction and hydrogen storage (Aladjem, 1973). Their technological importance is related to a wide range of physical and chemical properties, such as optical, dielectric and diffusion, which in turn are sensitive to the oxide texture.

Thermodynamically one would expect the oxide scale on titanium to consist of a sequence of layers of $\mathrm{Ti}_{2} \mathrm{O}, \mathrm{TiO}, \mathrm{Ti}_{2} \mathrm{O}_{3}, \mathrm{Ti}_{3} \mathrm{O}_{5}, \mathrm{Ti}_{n} \mathrm{O}_{2 n-1}$ $(4<n<38)$ and $\mathrm{TiO}_{2}$ (Wahlbeck and Gilles, 1966). However, for reaction at near atmospheric pressures at $1173 \mathrm{~K}$, only the rutile modification of $\mathrm{TiO}_{2}$ with a tetragonal structure has been detected in the oxide scale (Czerwinski and Szpunar, 1998b). According to Kofstad 
(1988), one phase structure is formed due to kinetic reasons. Since various oxide phases exhibit different diffusion properties and are stable at different oxygen activities, the local equilibria are slow to be established under dynamic oxidation conditions. Apparently the rates of oxygen dissolution and rutile formation are much faster than the rates of formation of the lower oxides.

The X-ray measurements show that the rutile scales have a texture of

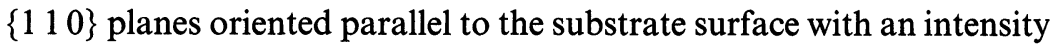
of 6.7 times random (Fig. 4). The contribution of the second texture component, $\langle 211\rangle$ fibre, is relatively small. The symmetrically located maxima on the $\left\{\begin{array}{lll}1 & 1 & 0\end{array}\right\}$ pole figure indicate the special alignment between $\mathrm{TiO}_{2}$ grains. It is possible that this orientation results from the epitaxial relationship between oxide and $\mathrm{Ti}$ grains in the metallic substrate. At temperatures above $1155 \mathrm{~K}$, Ti should essentially exist as a $\beta$ (b.c.c.) allotropic modification (Wahlbeck and Gilles, 1966). However, at high temperatures, oxygen dissolves in the metal. This observation is supported by a shift of $(100) \mathrm{Ti}$ peak towards the lower theta value (Czerwinski and Szpunar, 1998b). Since the dissolved oxygen generally

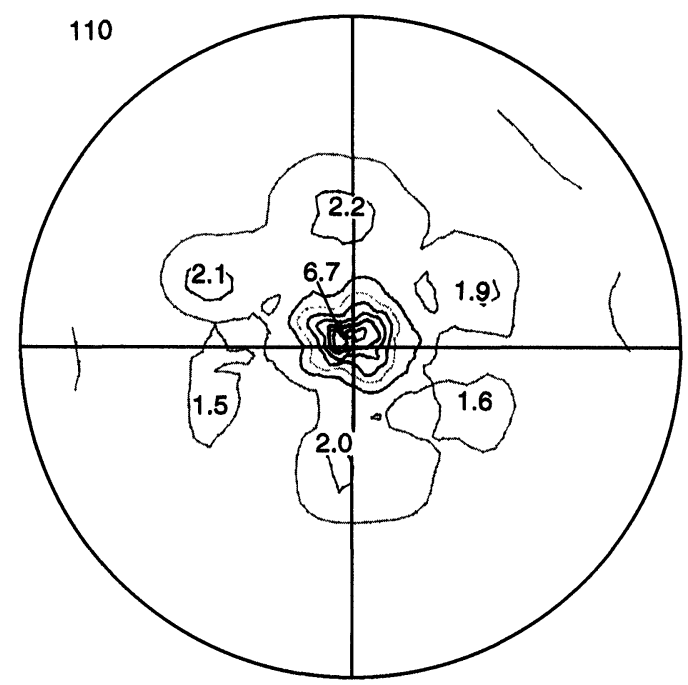

a) Contour: $1-, 1.8-, 2.6-, 3.4-, 4.2-, 5-, 5.8-$

FIGURE 4(a) 


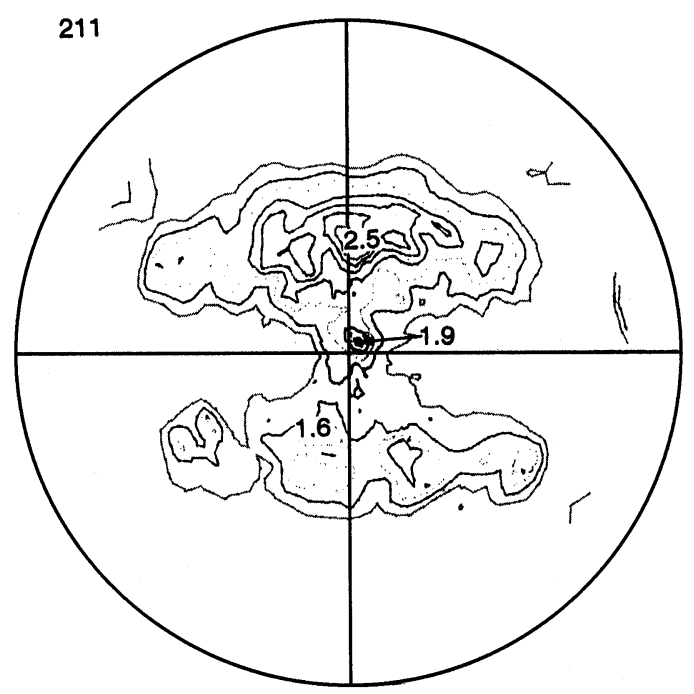

b) Contour: $1-, 1.2-, 1.4-, 1.6-, 1.8-, 2-, 2.2-$

FIGURE 4(b)

FIGURE 4 Texture of rutile $\left(\mathrm{TiO}_{2}\right)$ grown on pure titanium at $1173 \mathrm{~K}$ (Czerwinski and Szpunar, 1998b).

stabilizes the $\alpha$ phase with h.c.p. structure, one should rather expect the epitaxy is formed between the hexagonal $\alpha \mathrm{Ti}$ and tetragonal $\mathrm{TiO}_{2}$.

\section{ROLE OF GRAIN BOUNDARY STRUCTURE IN OXIDE GROWTH}

The density and structure of grain boundaries in protective oxides have an important influence on the oxidation resistance of many industrial materials. In transition metals, such as $\mathrm{Ni}, \mathrm{Cr}$ and $\mathrm{Fe}$, this is particularly true at temperatures lower than approximately half of the melting point of oxide under consideration. There is a good deal of evidence that the growth of the majority of oxides at these temperatures takes place by diffusion along so-called "short circuit paths" which are mainly grain boundaries and dislocations (Smeltzer, 1989; Czerwinski and Smeltzer, 1993). This implies the formation of finer grained oxide structure at higher growth rates. Atkinson et al. (1982) determined the following 
expression to calculate the rate constant $\left(k_{\mathrm{pc}}\right)$ for $\mathrm{NiO}$ growth:

$$
k_{\mathrm{pc}}\left(1 \mathrm{~atm} \mathrm{O}_{2}\right)=6.4\left\{D_{1}+2\left(D_{\mathrm{gb}} \delta\right) / g\right\}\left(\mathrm{cm}^{2} / \mathrm{s}\right)
$$

where $D_{1}$ is lattice diffusion coefficient, $D_{\mathrm{gb}} \delta$ is the product of the grain boundary diffusion coefficient and grain boundary width, and $g$ is the oxide grain size. According to our measurements (Czerwinski and Szpunar, 1995), for Ni oxidized at $873 \mathrm{~K}$, the difference between rate constants calculated for lattice diffusion and measured experimentally is almost four orders of magnitude. For $\mathrm{Cr}_{2} \mathrm{O}_{3}$ oxides we still do not have precise diffusion data.

To use the Eq. (1) for strongly textured oxides, it is necessary to know the diffusion coefficient for specific grain boundaries. It is clear that the diffusivity of oxide grain boundaries is affected by their structure. The sharp crystallographic texture will lead to higher proportion of grain boundaries with low diffusivity ( $\mathrm{Li}$ et al., 1997). In particular, the proximity of grain boundaries to a coincidence orientation will have an important influence on the diffusion rate. To describe the grain boundary character in oxide, the grain misorientation function and the frequency of CSL boundaries can be calculated from experimental ODF data.

Since oxidation is a surface phenomenon, the improvement in oxidation resistance may be obtained by modifying the texture of the surface layer of material. In the case of $\mathrm{Ni}$ and its alloys, an increase in strength of $\{111\}$ component results in a significant increase in the oxidation resistance (Czerwinski et al., 1996a; Czerwinski and Szpunar, 1996). To achieve this, various techniques of surface treatments, followed by annealing can be used. In some specific cases, the additional layer of metal may be deposited using techniques that allow to control the texture.

\section{SUMMARY}

The properties of electrolytic coatings depend on their crystallographic texture. The texture of Ni, Ni-based, Fe, Fe-based and $\mathrm{Zn}$-based coatings can easily be modified by electrodeposition conditions. The oxidation rates of polycrystalline $\mathrm{Ni}$ and $\mathrm{Ti}$ depend on crystallographic texture and 
surface finishing. For high-purity $\mathrm{Ni}$, oxidized at temperature below $1300 \mathrm{~K}$, the differences in oxide growth on differently oriented crystal faces reach up to one order of magnitude. These differences are caused by the microstructure of oxide and in particular grain size and grain boundary structure. Modification of substrate texture can be an effective way to improve oxidation resistance of metals and alloys.

\section{Acknowledgment}

This work was financially supported by the Natural Sciences and Engineering Research Council of Canada.

\section{References}

Aladjem, A. (1973) J. Mater. Sci., 8, 688-694.

Amblard, J., Froment, M. and Spyrelis, N. (1977) Surf. Technol., 5, 205-210.

Atkinson, A.T., Taylor, R.I. and Hughes, A.B. (1982) Phil. Mag. A, 45, 823-833.

Bunge, H.J. (1991) Textures and Microstr., 14-18, 283-326.

Cathcart, J.V., Petersen, G.F. and Sparks, C.J. (1969) J. Electrochem. Soc., 116, 664-668.

Czerwinski, F. and Smeltzer, W.W. (1993) J. Electroch. Soc., 140, 2606-2615.

Czerwinski, F., Sproule, G.I., Graham, M.J. and Smeltzer, W.W. (1995a) Corros. Sci., 37, 541-556.

Czerwinski, F., Szpunar, J.A., Macaulay-Newcombe, R.G. and Smeltzer, W.W. (1995b) Oxid. Metals, 43, 25-57.

Czerwinski, F. and Szpunar, J.A. (1995) Canad. Metall. Quart., 34, 243-249.

Czerwinski, F. and Szpunar, J.A. (1996) Thin Solid Films, 289, 213-219.

Czerwinski, F., Szpunar, J.A. and Smeltzer, W.W. (1996a) J. Electroch. Soc., 143, 3000-3007.

Czerwinski, F., Zielinska-Lipiec, A. and Szpunar, J.A. (1996b) In Textures of Materials ICOTOM 11 (Ed. Z. Liang et al.) Inter. Acad. Publ., Beijing, China, pp. 1132-1136.

Czerwinski, F., Kondo, K. and Szpunar, J.A. (1997a) J. Electroch. Soc., 144, 4810-484.

Czerwinski, F., Kondo, K. and Szpunar, J.A. (1997b) In Electrochemical Synthesis and Modification of Materials (Ed. P. Andricacos et al.) MRS Pittsburgh, PA, 451, pp. 445-450.

Czerwinski, F., Li, H., Megret, F., Szpunar, J.A., Clark, D.G. and Erb, U. (1997c) Scripta. Mater., 37, 1967-1972.

Czerwinski, F. and Szpunar, J.A. (1998a) Acta. Mater., 46, 1403-1417.

Czerwinski, F. and Szpunar, J.A. (1998b) Micron, in press.

Kofstad, P. (1988) High Temperature Corrosion, Elsevier Applied Science Publ., London, pp. 289-299.

Kondo, K. (1994) Ph. D. Thesis, Kyoto University.

Leidheiser, H. and Kim, D.K. (1956) J. Metals, 28, 179-184.

Li, D.Y. and Szpunar, J.A. (1997a) Electroch. Acta, 42, 37-45.

Li, D.Y. and Szpunar, J.A. (1997b) Electroch. Acta, 42, 47-60.

Li, H., Czerwinski, F., Zhilyaev, A.P. and Szpunar, J.A. (1997) Corros. Sci., 39, 1211-1219.

Pangarov, N.A. (1962) Electrochim. Acta, 7, 139-146.

Park, H., Czerwinski, F. and Szpunar, J.A. (1996) Mater. Sci. Forum, 204-206, 703-708. 
Reddy, A.K. (1963) J. Electroanalyt. Chem., 6, 141-152.

Smeltzer, W.W. (1989) Mater. Sci. Forum, 29, 151-172.

Vlad, C.V., Dahms, M. and Bunge, H.J. (1987) Proc. 8th Confer. on Texture of Materials, Santa Fe, CA. The Metallurgical Society of AIME, 855-860.

Volmer, M. (1921) Z. Physik, 5, 31-43.

Wahlbeck, P.G. and Gilles, P.W. (1966) J. Am. Ceram. Soc., 49, 180-184. 